\title{
Effect of Virtual Social Networks on Nursing Students' English
}

\section{Learning}

\author{
Rahele Sarikhani, ${ }^{1}$ Saeeid Moosavipour,, ${ }^{2,}$ Narges Feizabadi, ${ }^{3}$ and Mohammad Zare ${ }^{4}$ \\ ${ }^{1}$ Yong Researchers and Elite Club, Malayer Branch, Islamic Azad University, Malayer, IR Iran \\ ${ }^{2}$ Faculty of Humanities, Arak University, Arak, IR Iran \\ ${ }^{3}$ Young Researchers and Elite Club Karaj Branch, Islamic Azad University, Karaj, IR Iran \\ ${ }^{4}$ Faculty of Psychology and Education, Allameh Tabataba'i University, Tehran, IR Iran \\ "Corresponding author: Saeeid Moosavipour, Assistant Professor of Psychology, Faculty of Humanities, Arak University, Arak, IR Iran. E-mail: s-moosavipour@araku.ac.ir
}

Received 2016 November 02; Accepted 2016 December 24.

\begin{abstract}
Introduction: Development of new virtual technologies has evolved teaching-learning process. As for the technologies, it can be refered to the use of virtual social networks in education. The current study aimed at exploring the effect of using virtual social networks on nursing students English learning.

Methods: The current study employed pretest-posttest plan with control group. The research population consisted of all nursing students of Malayer nursing school, Malayer, Iran, in 2015-2016, among which 30 students were selected by available sampling method, and then, randomly assigned to the control and experimental groups. Instruments used in the research consisted of learning tests (pretest with 0.87 reliability and posttest with 0.89 via test-retest and confirmation of formal validity by English teachers as experts). Paired t test was employed to analyze data by SPSS version 18.

Results: The research findings showed that the learning level of students who learned English via virtual social networks was more than that of students who learned it traditionally ( $\mathrm{t}=14.30$ and plusmn; $2.48, \mathrm{P}=0.001)$.

Conclusions: Given the effect of virtual social networks on nursing students English learning, it is recommended to use this teaching technique in the teaching-learning process of medical education.
\end{abstract}

Keywords: Social Networks, Virtual, Learning, Education, Nursing

\section{Introduction}

Today, information and communication technologies penetrate into all social, organizational, and individual areas of human societies, and almost markedly affect individuals' lifestyle. Benefitting from these technologies is considered a paradigm shift in man's personal and social life, in which even concepts can be realized with the geometry of new knowledge. According to Castells, new information technologies link the points across the universe in the world of networks. Computer communications bring about a set of virtual communitiesthat evolve all material and spiritual structures and processes of human beings (1).

One of the tasks of an educational system is to nurture people with critical and creative thinking and problemsolving ability. Therefore, university teachers should apply methods probably quite different from the ones they were taught to teach something; that is, it is necessary to involve students actively and thoughtfully in the learning process (2). Benefitting from all possibilities and available rich technologies is integral to realization of such an approach, given the broad progress of knowledge in information technology (3). One of the practices of presentation, based on information and communication technology, is presentation of teaching via virtual social networks. Virtual social networks are a means of information and communication technology based on web 2 . Social media are introduced as internet networks providing an online com- munication for users to maintain quick and easy interactions (4).

Ellison and Boyd define social networks as web-based service sites allowing people to build a profile, interact with users and search in the list of communications (5). In another definition, experts defined virtual social networks as online communities of internet users who intend to communicate with other users in the areas of interest to both sides (6). Today, students' wide acceptance of virtual social networks provides a unique opportunity to explore the functional effects of the media on their educational capabilities (7). Education in medical sciences plays a crucial role in the training of medical health workforce in the country. Promotion of educational level can increase the level of public health, and help to improve the process of treatment (8). A host of factors affect students' training in disciplines of medical education, such as the application of the new methods of information and communication technology in their teaching-learning process. Inasmuch as the use of the networks is an integral part of many students' lives, with the advent of social networks, all living dimensions of students including level of study and their educational performance are directly affected $(9,10)$.

Web 2 technology offers miscellaneous opportunities and potential functions to students. As teacher and classroom are the mere medium by which a foreign language learning can take place, web 2 instrument offers another medium for interesting, learning-focused, and dynamic 
activities. Moreover, the tools offer situations where writing, comprehension, conversation, and listening skills are practiced inside and outside classroom environment (11). Since the introduction of the concept of web 2 by Darcy Dinochi in 1999, many studies were conducted on the application of the tools in second language teaching (12). Since the advent of social networks, many experts such as Pasek et al. (13), Schwartz et al. (14), Mazur and Richards (15), Yang (16), Selwyn (17), Robblyer et al. (18), and Hung and Yuen (19) studied their application in educational contexts. All of these researchers came to the conclusion that social networks build up group critical thinking, group projectfocused learning and problem solving via internet instruments, and providing the possibility of new knowledge production. Moreover, review of the conducted research indicates that social networks can turn into strong instruments to create a constructive approach-based learning environment. Some studies were conducted on virtual social networks regarding pedagogical issues.

Khani and Boghayeri, in a research entitled "Investigating the Efficacy of Web 2 Tools on Language Pedagogy in Iran", found that web 2 instruments had a positive impact on academic achievements of the English language learning (11).

Javadinia et al., in a research entitled "Effects of Social Networks on Academic Achievements of Students at Birjand University of Medical Sciences", concluded that application of virtual social networks can enhance students' academic achievements, but of the way to use the technology should be introduced to students at the beginning of their university admission (8).

Christine et al., in a research entitled "Use of Social Media in Medical Pedagogy", found that application of social networks can improve knowledge, attitude, and writing skills (20). Based on the studies conducted on the application of virtual social networks in learning-teaching processes, virtual social networks can bring about pedagogical efficacy if employed properly, and build up learners' academic achievements. The current research aimed at exploring the effect of virtual social networks on nursing students' Englishlearning. The research hypothesis holds that application of virtual social network affects nursing students' English language pedagogy.

\section{Methods}

The present research was a quasi-experimental research with pretest-posttest plan and control group. The study population consisted of all female and male nursing students at nursing school in Malayer University of Medical Sciences, Malayer, Iran, in the academic year 20152016. Among this statistical population, 30 students were selected via available sampling and randomly assigned into the control and experimental groups. All cases were undergraduate students of nursing admitted in the first semester of the academic year 2014 - 2015.

The inclusion criteria were willingness to participate and taking an English language course in the semester. The exclusion criterion was lack of desire to participate in the research. In the beginning, the pretest was administered among both groups. Then, the control group received English language tips which included vocabulary and grammar traditionally-classic classroom method-in the form of textbook matched with educational contents in virtual format, which includes vocabulary and grammar, and the experimental group received the same tips via the social network Telegram, which included vocabulary and grammar in the form of picture, text, voice, and use of PowerPoint. The subjects of the experimental group who received training via the virtual network could interact with one another and contribute to learning. They were taugh 10 one-hour sessions. Following the course, either group was given an English language posttest. Afterward, the independent $t$ test was employed to analyze the obtained data by SPSS version 18. The applied instruments in the research included English language learning tests, ie, pretest and posttest. Either of the tests contained 20 objective items of academic general English and the formal validity was confirmed by 3 English language teachers and the reliability was calculated by Cronbach's alpha (pretest: 0.87 , posttest: 0.89 ).

The score range was 0 to 20 . The inclusion criterion was the willingness to participate in the research. It should be noted that all the participants were informed about the research goals and they expressed their oral consent.

In descriptive statistics, indexes such as mean, standard deviation, and in inferential statistics independent $t$ test was used to test the research hypotheses.

\section{Results}

From the research statistical population, 30 students were selected as research sample. Out of this, 6.76 students were female and 7 (3.23) were male. The current research aimed at investigating the effect of using virtual social networks on nursing students' English learning. Thus, the research hypothesis holds that application of virtual social networks affects nursing students' English language pedagogy.

According to Table 1, the pretest mean scores of subjects were not significantly different. However, in the posttest, the mean scores in both control and experimental groups increased, not mentioned if it was significant.

According to Table 1, pretest scores of the 2 groups were not significantly different, but the posttest scores of the 2 
Table 1. Paired $t$ Test of Pretest and Posttest of Both Groups ${ }^{\mathrm{a}}$

\begin{tabular}{|c|c|c|c|c|c|c|}
\hline \multirow[t]{2}{*}{ Variable } & \multicolumn{3}{|c|}{ Control } & \multicolumn{3}{|c|}{ Experimental } \\
\hline & Posttest & Pretest & PValue & Posttest & Pretest & P Value \\
\hline Learning & $8 \pm 2.34$ & $9.50 \pm 2.56$ & 0.784 & $7.80 \pm 2.33$ & $14.30 \pm 2.48$ & $<0.001$ \\
\hline
\end{tabular}

groups were significantly different $(\mathrm{P}=0.001)$. Therefore, with 95\% interval confidence (IC), the null hypothesis was rejected and then the research hypothesis about the effect of virtual social networks on nursing students' English language learning level was accepted.

\section{Discussion and Conclusion}

The current research aimed at exploring the effect of virtual social networks on nursing students' English language learning. The research finding indicated that the application of virtual social networks in nursing students' English language learning increased their learning level. The research finding was in line with those of Pasek et al. (13), Schwartz et al. (14), Mazur and Richards (15), Yang (16), Selwyn (17), Roblyer (18), Hung and Yuen (19), which suggest that social networks via internet instruments can build up group critical thinking, group projectbased learning, and problem solving and allow for new knowledge production. As a matter of fact, the studies emphasize the constructive approach of social networks and pay attention to the active role of learners. Furthermore, the result of the research was in line with that of Khani and Boghayeri (11) who concluded that use of webbased instruments exerts positive influence on students' academic achievement regarding English language learning, that of Javadinia et al. (8) who indicated that application of virtual social networks can contribute to students' academic achievement, and that of Cheston et al. (20) who concluded that application of social networks can improve knowledge, attitude and writing skills. The factor of virtual social networks in the improvement of nursing students' English language learning can be found in the main features of social networks namely interactive and participating quality and possibility of multimedia application, and more importantly constructive-based approach of this pedagogical media. In constructive-based approach, the students themselves are responsible for their learning, and activity factor can improve their learning in learningteaching process.

Given the result of the research, administrators involved in higher education and particularly medical education are recommended to employ this technology for pedagogical purposes.

\section{Footnotes}

Author's Contribution: All authors participated in the study, equally.

Conflict of Interest: There was no conflict of interest for the current study.

\section{References}

1. Mohkamkar I, Halaj MM. What are social networks?. Secur Knowledge North Khorasan. 2014;1(2):87-108.

2. Sheykhzade M, Samari S. University Professor teaching methods West Azarbaijan Islamic Azad University. Educ Administ Q Res. 2010;3(3):7194.

3. Safariyan S, Falah V, Mirhosyni H. Comparison of the effect of the aid Educational software and traditional teaching and learning mathematics. Inf Commun Technol Educ. 2010;1(2):21-36.

4. Ahmed A. Social networking sites and its popularity. Int J Res Rev Comput Sci. 2011;2(2):522-6.

5. Davis Iii CHF, Deil-Amen R, Rios-Aguilar C, Gonzalez Canche MS. Social Media, Higher Education, and Community Colleges: A Research Synthesis and Implications for the Study of Two-Year Institutions. Commun College J Res Pract. 2014;39(5):409-22. doi: 10.1080/10668926.2013.828665.

6. William FP. Social networking sites: How to Stay Safe Sites. Multi-State Information Sharing \& Analysis Center (MS-ISAC); 2009.

7. Aryani E, ZAHED BA, MOENIKIA M, Khaleghkhah A. The role of virtual social networks in the research capabilities of postgraduate students. MEDIA. 2015;6(2):26-39.

8. Javadinia S, Erfanian M, Abedini M, Bijari B. The Effects of Social Networks on Academic Achievement of Students, a Study in Birjand University of Medical Sciences. Iran J Med Educ. 2012;12(8):598-606.

9. Kirschner PA, Karpinski AC. Facebook $₫$ and academic performance. Comput Human Behav. 2010;26(6):1237-45. doi: 10.1016/j.chb.2010.03.024.

10. Thompson LA, Dawson K, Ferdig R, Black EW, Boyer J, Coutts J, et al. The intersection of online social networking with medical professionalism.J Gen Intern Med. 2008;23(7):954-7. doi: 10.1007/s11606-008-05388. [PubMed: 18612723].

11. Khani R, Boghayeri M. Investigating the Efficacy of Web 2 Tools on Language Pedagogy in Iran.J Technol Educ. 2014;9(2):115-21.

12. Abdous M, Facer BR, Yen CJ. Academic effectiveness of podcasting: A comparative study of integrated versus supplemental use of podcasting in second language classes. Comput Educ. 2012;58(1):43-52. doi: 10.1016/j.compedu.2011.08.021.

13. PasekJ, More E, Hargittai E. Facebook and academic performance: Reconciling a media sensation with data. First Monday. 2009;14(5) doi: 10.5210/fm.v14i5.2498.

14. Schwartz JL, Donovan J, Guido-DiBrito F. Stories of Social Class: SelfIdentified Mexican Male College Students Crack the Silence.J College Student Dev. 2009;50(1):50-66. doi: 10.1353/csd.0.0051.

15. Mazur E, Richards L. Adolescents' and emerging adults' social networking online: Homophily or diversity?. J Appl Dev Psychol. 2011;32(4):180-8. doi: 10.1016/j.appdev.2011.03.001. 
16. Yang YTC. A catalyst for teaching critical thinking in a large university class in Taiwan: asynchronous online discussions with the facilitation of teaching assistants. Educ Technol Res Dev. 2007;56(3):241-64. doi: 10.1007/s11423-007-9054-5.

17. Selwyn N. Web 2.0 applications as alternative environments for informal learning-a critical review. Paper for CERI-KERIS International Expert Meeting on ICT and Educational Performance. ; 2007.

18. Roblyer MD, McDaniel M, Webb M, Herman J, Witty JV. Findings on Facebook in higher education: A comparison of college faculty and student uses and perceptions of social networking sites. Internet High Educ. 2010;13(3):134-40. doi:10.1016/j.iheduc.2010.03.002.

19. Hung HT, Yuen SCY. Educational use of social networking technology in higher education. Teach High Educ. 2010;15(6):703-14. doi: 10.1080/13562517.2010.507307.

20. Cheston CC, Flickinger TE, Chisolm MS. Social media use in medical education: a systematic review. Acad Med. 2013;88(6):893-901. doi: 10.1097/ACM.0b013e31828ffc23. [PubMed: 23619071]. 